\title{
PENGARUH SERVICE QUALITY DAN CUSTOMER ENGAGEMENT TERHADAP MINAT NASABAH UNTUK MENGGUNAKAN PRODUK PT BANK CENTRAL ASIA DI JAKARTA
}

\author{
Ayu Wulandari \\ Program Studi Magister Manajemen Universitas Tarumanagara \\ ayuwulandari182@gmail.com
}

Masuk : 07-12-2019, revisi : 07-01-2020 diterima untuk diterbitkan : 07-01-2020

\begin{abstract}
The purposes of this journal article namely are: 1) To determine the effect of service quality on customer intention to use the products of BCA; and 2) To determine the effect of customer engagement on customer intention to use the products of BCA. This research is a descriptive type with cross sectional method. The data used are primary data obtained from distributing questionnaires directly to the research sample. The study population consisted of all customers conducting transactions at Bank BCA KCP Samanhudi Jakarta. The research sample was determined using the non-probability method with accidental sampling (convenience sampling) technique and obtained a total sample of 175 respondents. The research data were analyzed using multiple linear regression tests.

The results of the study stated that service quality has a positive and significant effect on customer interests. The higher the service quality provided by BCA banks, the higher the intention of customers to use the products of BCA. Other results state that customer engagement has a positive and significant effect on customer intention. The higher ccustomer engagement, the higher the customer intention in using BCA products.
\end{abstract}

Abstrak : Tujuan dari artikel jurnal ini yaitu: 1) Untuk mengetahui pengaruh kualitas layanan terhadap niat pelanggan untuk menggunakan produk-produk BCA; dan 2) Untuk mengetahui pengaruh keterlibatan pelanggan terhadap niat pelanggan untuk menggunakan produk-produk BCA. Jenis penelitian ini adalah deskriptif dengan metode cross sectional. Data yang digunakan adalah data primer yang diperoleh dari penyebaran kuesioner langsung ke sampel penelitian. Populasi penelitian terdiri dari semua pelanggan yang melakukan transaksi di Bank BCA KCP Samanhudi Jakarta. Sampel penelitian ditentukan dengan menggunakan metode non-probabilitas dengan teknik accidental sampling (convenience sampling) dan diperoleh total sampel 175 responden. Data penelitian dianalisis menggunakan uji regresi linier berganda.

Hasil penelitian menyatakan bahwa kualitas layanan memiliki pengaruh positif dan signifikan terhadap minat pelanggan. Semakin tinggi kualitas layanan yang diberikan oleh bank BCA, semakin tinggi minat pelanggan untuk menggunakan produk-produk BCA. Hasil lain menyatakan bahwa keterlibatan pelanggan memiliki pengaruh positif dan signifikan terhadap minat pelanggan. Semakin tinggi keterlibatan pelanggan, semakin tinggi minat pelanggan dalam menggunakan produk BCA.

Keywords : Service Quality, Customer Engagement, Minat Beli, Bank BCA

\section{PENDAHULUAN}

Seiring dengan semakin meningkatnya persaingan bisnis perbankan, Bank BCA terus berupaya untuk meningkatkan mutu pelayanannya yang salah satunya dengan cara menerapkan program service excellence atau pelayanan prima. Pelayanan prima tersebut dilakukan agar menarik minat nasabah untuk menggunakan produk yang ada di BCA.

Minat beli sangat penting untuk diteliti karena dengan adanya minat beli atau minat dari nasabah dalam menggunakan produk jasa yang diberikan, dan dalam hal ini adalah minat 
menggunakan produk BCA secara umum dapat mempengaruhi bisnis dari perbankan khususnya BCA. Berdasarkan uraian tersebut, maka artikel jurnal ini ditulis dengna judul "Pengaruh Service Quality dan Customer Engagement terhadap Minat Nasabah untuk Menggunakan Produk PT Bank Central Asia di Jakarta."

\section{Tujuan Penelitian}

Sesuai dengan pemaparan pada bagian pendahuluan di atas, maka artikel jurnal ini ditulis dengan beberapa tujuan sebagai berikut:

1. Untuk mengetahui pengaruh service quality terhadap minat nasabah dalam menggunakan produk yang ada di BCA.

2. Untuk mengetahui pengaruh customer engagement terhadap minat nasabah dalam menggunakan produk yang ada di BCA

\section{TELAAH KEPUSTAKAAN}

\section{Service Quality}

Sesuai dengan konteks penelitian ini, maka model service quality (servqual) yang digunakan adalah yang spesifik pada kondisi perbankan. Model service quality (servqual) pada perusahaan perbankan menurut Markovic, et al. (2015) menjelaskan mengenai kemampuan perbankan untuk memberikan pelayanan yang dapat meningkatkan kepuasan setiap nasabah. Lebih lanjut dijelaskan oleh Markovic, et al. (2015), service quality pada perusahaan perbankan dapat dijelaskan melalui 6 dimensi, yang dijelaskan sebagai berikut.

1. Tangibles, merupakan dimensi yang menjelaskan layanan berupa lingkungan fisik dan penampilan dari pegawai bank.

2. Reliability, merupakan dimensi yang menjelaskan kemampuan bank untuk menyediakan layanan yang akurat dan dapat diandalkan oleh nasabah.

3. Responsiveness, dimensi yang menjelaskan kesediaan bank untuk membantu nasabah dengan memberikan pelayanan yang cepat.

4. Assurance, dimensi yang menjelaskan kemampuan pegawai bank untuk dapat membangun kepercayaan dengan nasabah.

5. Empathy, dimensi yang menjelaskan kemampuan bank untuk memberikan perhatian secara pribadi kepada setiap nasabah. I

6. Availability, dimensi yang menjelaskan kemampuan bank untuk dapat memberikan pelayanan yang mudah dijangkau oleh setiap nasabah.

\section{Customer Engagement}

Customer engagement dapat didefinisikan sebagai perilaku pelanggan yang terbentuk karena didasari pada hubungannya dengan suatu perusahaan atau merek (Palmatier, Kumar, dan Harmeling, 2018, p.175). Menurut pendapat lain, customer engagement merujuk pada setiap interaksi aktif yang terjadi antara pelanggan dan perusahaan (Zyminkowska, 2018, p.25). Penentuan mengenai customer engagement dijelaskan melalui tiga dimensi berikut:

1. Emotional engagement, dimensi yang menjelaskan mengenai keterikatan emosi yang terjalin antara pihak bank dengan nasabah. Keterikatan emosional yang dimaksud adalah kemauan nasabah untuk bersikap untuk mendukung produk dan layanan perusahaan perbankan. Indikator yang digunakan meliputi: (a) sikap yang selalu antusias.

2. Cognitive engagement, dimensi yang menjelaskan mengenai keterikatan secara kognitif yang terjalin antara pihak bank dengan nasabah. Cognitive engagement cenderung menunjukkan pembentukan nilai yang dilakukan oleh perbankan kepada setiap nasabah.

3. Behavioural engagement, dimensi yang menjelaskan mengenai keterikatan secara perilaku yang terjalin antara pihak bank dengan nasabah. Keterikatan yang dimaksud adalah kemauan nasabah untuk melakukan perubahan perilaku yang sesuai dengan harapan perusahaan perbankan. 


\section{Minat Beli}

Minat beli adalah kencederungan yang mendasari keputusan pelanggan untuk melakukan suatu pembelian, yang dapat dipengaruhi oleh adanya beragam pililhan atau karena pelanggan sedang berada pada situasi tertentu. Minat beli dapat terbentuk ketika pelanggan sedang berada pada situasi tertentu dan dihadapkan pada beberapa alternatif pilihan produk. Dalam hal ini, semakin tinggi minat beli terhadap suatu produk akan menjadi penentu keputusan pelanggan untuk membeli atau menggunakan produk tersebut (Kotler dan Keller, 2012:113; Chen, Chen, dan Tung, 2018, p.5; Mirabi, Akbariyeh, dan Tahmasebifard, 2015, p.268).

\section{Penelitian Terdahulu}

Beberapa penelitian terdahulu yang menjadi acuan penulisan artikel jurnal ini antara lain: Yoong dan Lian (2019) dalam penelitiannya yang berjudul "Consumer Engagement in Social Media and Purchase Intentions in the Hotel Industry" dengan tujuan penelitian untuk menganalisis pengaruh dari consumer engagement di media sosial terhadap consumer intention to purchase in the hotel industry in Malaysia. Jenis penelitian kuantitatif dengan menggunakan sampel sebanyak 392 pelanggan hotel di Malaysia. Data penelitian dikumpulkan menggunakan kuesioner dan di analisis menggunakan SPSS untuk melaksanakan analisis deskripsi, validitas dan reliabilitas, serta menggunakan SEM untuk menguji hipotesis penelitian. Hasil penelitian menyatakan bahwa consumer-brand engagement dan brand experience berpengaruh signifikan terhadap consumer purchase intention.

\section{Hipotesis Penelitian}

Sesuai dengan pemaparan teori dan hasil-hasil penelitian terdahulu yang memiliki relevansi dengan penelitian ini, maka hipotesis yang dikembangkan dalam penelitian ini adalah:

H 1: Service Quality berpengaruh positif terhadap minat nasabah dalam menggunakan produk BCA

$\mathrm{H}$ 2: Customer Engagement berpengaruh positif terhadap minat nasabah dalam menggunakan produk BCA

\section{METODOLOGI PENELITIAN}

Penelitian ini berjenis deskriptif dengan metode cross sectional. Penelitian deskriptif adalah penelitian yang bertujuan untuk mendeskripsikan karakteristik dari sebuah peristiwa yang terjadi (Noor, 2016). Metode cross sectional adalah adalah suatu studi penelitian dengan data yang dikumpulkan hanya sekali (dari bentang waktu tertentu bisa selama hari, waktu, dan bulan) untuk menjawab pertanyaan dari suatu penelitian. Periode penelitian ini dilakukan pada bulan Oktober 2019 dengan menggunakan kuesioner dengan jumlah responden sebanyak 175 responden.

\section{HASIL PENELITIAN DAN PEMBAHASAN}

Berdasarkan hasil pengisian kuesioner sebagian besar responden berjenis kelamin lakilaki (65\%), sedangkan sisanya sebanyak 35\% responden berjenis kelamin perempuan, selanjutnya berdasarkan pendidikan responden hasil analisis menunjukkan sebagian besar responden berpendidikan sarjana (45\%), sedangkan sisanya sebanyak $27 \%$ responden berpendidikan SMA/sederajat, sebanyak 1\% responden berpendidikan lain - lian, sebanyak $23 \%$ responden berpendidikan pascasarjana dan sebanyak $4 \%$ responden berpendidikan doktor, selanjutnya berdasarkan pekerjaan responden hasil analisis menunjukkan bahwa sebagian besar respodnen merupakan pegawai swasta $(65 \%)$, sedangkan sisanya sebanyak $6 \%$ adalah pengusaha, sebanyak $8 \%$ adalah ibu rumah tangga dan sebanyak $6 \%$ responden adalah pedagang. 
Dalam penelitian ini, pengaruh service quality dan customer engagement terhadap minat nasabah akan dianalisis dengan analisis regresi linear berganda. Tahap - tahap dalam analisis regresi linear berganda meliputi tahap uji asumsi klasik dan tahap uji model regresi yang meliputi uji t, uji F dan pengujian terhadap koefisien determinasi.

Berdasarkan hasil uji pengaruh parsial service quality terhadap minat nasabah, hasil analisis menunjukkan bahwa nilai signifikan pengaruh variabel service quality terhadap minat nasabah adalah sebesar 0,012 dengan koefisien regresi bertanda positif. Oleh karena nilai signifikan yang diperoleh $<0,05$ dan koefisien regresi bertanda positif maka Ho ditolak dan disimpulkan bahwa service quality berpengaruh positif dan signifikan terhadap minat nasabah. Dan berdasarkan hasil pengujian customer engagement terhadap minat nasabah, hasil analisis menunjukkan bahwa nilai signifikan pengaruh variabel customer engagement terhadap minat nasabah adalah sebesar 0,000 dengan koefisien regresi bertanda positif. Oleh karena nilai signifikan yang diperoleh $<0,05$ dan koefisien regresi bertanda positif maka Ho ditolak dan disimpulkan bahwa customer engagement berpengaruh positif dan signifikan terhadap minat nasabah

\section{PENUTUP}

Kesimpulan yang dapat diambil dari pembahasan artikel jurnal ini antara lain:

1. Service quality berpengaruh positif dan signifikan terhadap minat nasabah. Semakin tinggi service quality yang diberikan bank BCA, maka semakin tinggi minat nasabah menggunakan produk bank BCA

2. Customer engagement berpengaruh positif dan signifikan terhadap minat nasabah. Semakin tinggi customer engagement nasabah, maka semakin tinggi minat nasabah menggunakan produk bank BCA

Adapun saran yang dapat diberikan adalah sebagai berikut:

1. Bagi Bank BCA

Service quality dan customer engagement terbukti berpengaruh terhadap minat nasabah bank, dengan demikian, untuk terus meningkatkan minat nasabah menggunakan produk bank BCA maka bank BCA harus dapat selalu memberikan service quality yang baik dan membangun customer engagement yang tinggi.

2. Bagi Peneliti Selanjutnya

a. Peneliti menyarankan agar penelitian tidak hanya di lakukan di Bank BCA KCP Samanhudi saja akan tetapi dapat dilakukan di seluruh Bank BCA di Jakarta

b. Peneliti menyarankan agar penelitian selanjutnya sebaiknya dilakukan dengan mengambil variabel selain service quality, customer engagement yang diduga dapat berpengaruh terhadap minat nasabah, sebagai variabel tambahan.

\section{DAFTAR PUSTAKA}

Ahmad, W., Hussain, S., Sanaullah, Jafar, M. S., \& Latif, W. U. (2017). Impact of E-Service Quality on Purchase Intention Through Mediator Perceived Value in Online Shopping. Journal of Information Engineering and APplication, 7(8), 23-28.

Arslan, M., \& Zaman, R. (2014). Impact of Brand Image and Service Quality on Consumer Purchase Intention: A Study of Retail Store in Pakistan. Research on Humanities and Social Science, 4(22), 98-106.

Chen, C.-C., Chen, C.-W., \& Tung, Y.-C. (2018). Exploring the Consumer Behavior of Intention to Purchase Green Products in Belt and Road Countries: An Empirical Analysis. Sustaiability, 10(854), 1-18.

Dwivedi, A. (2015). A higher-order model of consumer brand engagement and its impact on loyalty intentions. Journal of Retailing and Consumer Services, 24, 100-109. 
Eman, C., Pangemanan, S., \& Rumokoy, F. S. (2018). Analyzing the Effect of Service Quality and Perceived RIsk on Purchase Intention in the Multimart Convenience Store Tomohon City. Jurnal EMBA, 6(4), 2477-2487.

Hassan, H., Hashmi, M. S., \& Sarwar, Z. (2014). Exploring the Impact of Retail Stores' Service Quality on Consumers' Purchase Intention: The Moderating Role of CSR. Midle-East Journal of Scientific Research, 19(4), 505-520.

Kotler, P., \& Keller, K. L. (2012). Marketing Management, 14th Edition. Organization (Vol. 22).

Marković, S., Jelena, D., \& Katušić, G. (2015, January). Service Quality Measurement in Croatian Banking Sector: Application of SERVQUAL Model. In MIC 2015: Managing Sustainable Growth.

Mirabi, V., Akbariyeh, H., \& Tahmasebifard, H. (2015). A Study of Factors Affecting on Customers Purchase Intention Case Study: the Agencies of Bono Brand Tile in Tehran. Journal of Multidisciplinary Engineering Science and Technology, 2(1), 267-273.

Noor, S. E. (2016). Metodologi Penelitian: Skripsi, Tesis, Disertasi \& Karya Ilmiah. Prenada Media.

Palmatier, R. W., Kumar, V., \& Harmeling, C. M. (2018). CUstomer Engagement Marketing. USA: Palgrave Macmillan

Parasuraman, A. (2014). The Behavioral Consequences of Service Quality. New Jersey: Prentice Hall International, Inc

Pride, W. M., \& Ferrel, O. C. (2014). Marketing 2014. USA: Cencage-Learning

Risitano, M., Romano, R., Sorrentino, A., \& Quintano, M. (2017). Engagement valence duality and spillover effects in online brand communities. Journal of Service Theory and Practice, 27(4), 877-897.

Saidani, B., \& Arifin, S. (2012). Pengaruh Kualitas Produk dan Kualitas Layanan terhadap Kepuasan Konsumen dan Minat Beli pada Ranch market. Jurnal Riset Manajemen Sains Indonesia, 3(1), 1-22.

Yoong, L. C., \& Lian, S. B. (2019). Customer Engagement in Social Media and Purchase Intentions in the Hotel Industry. International Journal of Academic Research in Business \& Social Science, 9(1), 55-68.

Zeithaml, V. A., Bitner, M. J., \& Gremler, D. D. (2013). Services Marketing: Integrating Customer Focus Across the Firm 6th ed. Boston: McGraw-Hill.

Zyminkowska, K. (2018). Customer Engagement in Theory and Practice: A Marketing Management Perspective. Switzerland: Palgrave Macmillan. 